\title{
Study of operated primary and secondary (recurrence) hydatidosis in hospitals of Kermanshah, west of Islamic Republic of Iran
}

\author{
M. Vejdani, ${ }^{1,2}$ S. Vejdani, ${ }^{3}$ S. Lotfi, ${ }^{4}$ F. Najafi, ${ }^{5}$ N. Nazari ${ }^{1}$ and Y. Hamzavi ${ }^{1}$
}

$$
\begin{aligned}
& \text { دراسة حول الكيسات العدارية الأولية أو الثانوية (الناكسة) التي أجريت لما عمليات جر احية في مستشفيات كرمان شاه، غربيّ } \\
& \text { جمهورية إيران الإسلامية }
\end{aligned}
$$

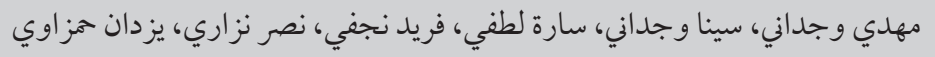

ABSTRACT Cystic echinococcosis, caused by the larval stage of Echinoccocus granulosus, is a global public health threat. The aim of this study was to determine the demographic and clinical characteristics of cases of primary and secondary hydatid cyst in the west of the Islamic Republic of Iran. A retrospective record review was made in 7 public and private hospitals in Kermanshah from 2004 to 2009. Of 526 files of suspected cases analysed, 291 cases of hydatid cyst had been operated upon and confirmed. Of the patients, $51.5 \%$ were females, $57.7 \%$ lived in urban and suburban areas and the largest age group $(17.5 \%)$ was $31-40$ years. The major organs involved were liver (64.9\%) and lung (26.8\%) and 18 cases $(6.2 \%)$ were confirmed as secondary hydatidosis. Most patients $(79.4 \%)$ had been treated with albendazole. Kermanshah province should be considered an endemic region for human hydatid cyst disease; greater efforts in prevention are needed.

Étude de I'hydatidose primaire et secondaire (récidive) opérée dans des hôpitaux de Kermanshah, dans l'ouest de la République islamique d'Iran

RÉSUMÉ L'échinococcose cystique, causée parle stade larvaire d'Echinoccocus granulosus, représente une menace pour la santé publique mondiale. L'objectif de la présente étude était de déterminer les caractéristiques démographiques et cliniques des cas de kyste hydatique primaire et secondaire dans l'ouest de la République islamiqued'Iran. UnerevuerétrospectivedesdossiersaétémenéedanssepthôpitauxpublicsetprivésdeKermanshah entre2004 et 2009.Suruntotalde526 dossiersdecassuspectsanalysés, 291 cas dekystehydatiqueavaientétéopérés etconfirmés.Lespatientsétaient 51,5 \%àêtre desexeféminin, 57,7 \%vivaientdansdeszonesurbainesousuburbaines et le groupe d'âge le plus nombreux (17,5\%) était celui des 31-40 ans. Les principaux organes touchés étaient le foie $(64,9 \%)$ et les poumons $(26,8 \%)$ et 18 cas $(6,2 \%)$ ont été confirmés comme hydatidose secondaire. La plupart des patients $(79,4 \%)$ avaient été traités par albendazole. La province de Kermanshah devrait être considérée comme une région d'endémie pour le kyste hydatique humain; des actions de prévention renforcées sont nécessaires.

'Department of Parasitology and Mycology, Faculty of Medicine; ${ }^{2}$ Cellular and Molecular Parasitology Research Centre, Faculty of Medicine; ${ }^{4}$ Department of Internal Medicine, Imam Reza's Hospital; ${ }^{5}$ Department of Statistics and Epidemiology, Faculty of Hygiene, Kermanshah University of Medical Sciences, Kermanshah, Islamic Republic of Iran (Correspondence to M. Vejdani: mvejdani@kums.ac.ir).

${ }^{3}$ Department of Biological Sciences, Faculty of Sciences, University of Calgary, Calgary, Alberta, Canada.

Received: 21/03/12; accepted: 09/05/12 


\section{Introduction}

Cystic echinococcosis, caused by the larval stage of Echinoccocus granulosus, is a global public health threat. The embryos penetrate the wall of the intestine and are carried in the bloodstream to vital organs such as the liver, the lungs or the brain, where they can form into watery blisters called hydatid cysts $[1,2]$. The disease presents a substantial burden on the human population. Current estimates suggest that cystic hydatid disease caused by E. granulosus results in the loss of 1-3 million disability-adjusted life years per annum. The annual cost of treating cases and economic loss to the livestock industry approximately amounts to US\$ 2 billion. These diseases are perhaps some of the more important global parasitic diseases, with more than 1 million people affected at any time [3].

Hydatid disease is endemic in sheep-raising areas of Africa, the Mediterranean region of Europe, the Middle East, Greece, Asia, South America, Australia and New Zealand $[4,5]$. The parasite has a very wide geographical distribution [6] and there is evidence for the emergence or re-emergence of human cystic echinococcosis in parts of China, Central Asia, Eastern Europe and Israel. E. granulosus is endemic too in the Islamic Republic of Iran, with stray dogs acting as the final host of the disease and sheep as the intermediate hosts. Human infections are regularly observed in medical centres in different parts of Islamic Republic of Iran $[7,8]$ but the western region of the country is more affected by this parasite than the other parts [9]. Some studies in single hospitals or isolated cases have been reported previously from other areas [10-12]. As there is limited information on the epidemiology of the disease in the west of the Islamic Republic of Iran, we aimed to study the demographic and clinical characteristics of cases of primary and secondary hydatid cyst in Kermanshah hospitals.

\section{Methods}

\section{Study design and setting}

A retrospective study from 2004-09 was performed in 7 private and public hospitals for tracking primary and secondary hydatid cyst in Kermanshah. The province of Kermanshah is located in the middle of the western part of the Islamic Republic of Iran, with a population of 1900831 in the last census in 2011. It is an agricultural and traditional livestock region of the country and women participate in the farming lifestyle as much as men. The province has a moderate mountainous climate and is suitable for husbandry of animals, particularly sheep. On the other hand, stray dogs, sheep and domestic herbivores in the mountain area and prairie have contributed to the existence of human and veterinary unilocular hydatid cyst.

\section{Data collection}

All documents were reviewed and files were analysed from all patients suspected to be infected with hydatid cyst who had been hospitalized and had undergone physical examination for clinical manifestations, computerized tomography scanning, magnetic resonance imaging, sonography and diagnostic laboratory testing by surgery specialists. Out of 526 files examined a total of 291 cases were reported to be infected with hydatid cyst. Data on age, sex, occupation, organs involved, primary or secondary recurrence of hydatid cyst and medication (albendazole-treated or not), were extracted from the hospital files. After surgery, oral albendazole $10 \mathrm{mg} / \mathrm{kg}$ or $400 \mathrm{mg}$ twice daily for 4 weeks was administrated, and repeated as necessary for up to 12 cycles, each separated by an interval of 2 weeks, repeated after 3-6 months.

\section{Data analysis}

The data was analysed with SPSS, version 16 , and simple descriptive statistics are reported.

\section{Results}

A total of 526 cases were studied in 7 hospitals during a 6-year period. Patients had undergone diagnosis based on clinical manifestations and 291 cases were operated on and verified with hydatid disease. Based on the most recent census data for the population of Kermanshah province (1 900831 ) this was an annual rate of approximately 2.6 per 100000 .

The principal sites of infection were the liver (64.9\%) and lung (26.8\%); 3 cases (1.0\%) were infected in both organs. Smaller numbers were infected in the pelvic area (5 cases, 1.7\%), while the remaining case involved the kidney, omentum, spleen, pancreas, gallbladder, prostate, bladder (3 cases each) and the uterus, mesentery or vertebrate (1 case each) (Table 1). Among these cases liver and lung involvement were reported at the highest rates.

The sex distribution showed 51.5\% females and $48.5 \%$ males (Table 1). Just over half of patients were from urban areas $(57.7 \%)$ and $42.3 \%$ were from residential rural areas. The age distribution indicated $6.9 \%$ of people infected were between 1-10 years of age and the oldest person diagnosed was 80 years old. The most prevalent age group for hydatid cyst disease was 31-40 years (17.5\%).

Out of 291 patients, 18 cases (6.2\%) were confirmed as secondary (recurrence) human hydatid cyst and $93.8 \%$ as primary hydatid cyst. Nearly three-quarters of patients with hydatidosis (73.2\%) underwent laparotomy and $26.8 \%$ underwent laparoscopy surgery. Albendazole was used after surgery on 231 cases (79.4\%). Albendazole medication lasted approximately 3 months and rarely over 6 months to 2 years. The recovery rate of hydatid cyst disease was $79.4 \%$.

\section{Discussion}

E. granulosus is a cosmopolitan parasite and endemic regions exist in each continent. Considerable public health 
problems occur in many areas, including countries of Central America, South America, Western and Southern Europe, Middle East, North Africa, subSaharan countries, China and Russia. Generally the Islamic Republic of Iran is an endemic area of hydatidosis $[13,14]$. Based on our data we estimated an annual rate of human hydatid cyst of 2.6 cases per 100000 people annually in hospitals in the province of Kermanshah. Another series reported the annual incidence of operated hydatidosis in Islamic Republic of Iran to be 4.8 per 100000 people [15]. An overall rate of 1.45 cases per 100000 people was reported in another study; the incidence was highest in Khorasan province (in the north-east of the country) with 4.45 cases per 100000 people and the lowest in Hormozgan province (in the south of the country) with 1 case per 100000 people [16]. The rate in other countries people were Greece (13 per $1000000)$, rural regions of Uruguay (75 per 1000000 ), rural regions of Argentina (143 per 1000 000), Xinjiang in China (197 per 1000000$)$ and Turkana in Kenya (220 per 1000 000) [17]. Neighbouring Turkey had 18-20 cases per 1000000 people [18]. Stray dogs represent a major threat for transmission to humans [19]; in Kermanshah, the prevalence of E. granulosus in dogs and red foxes were reported as $16.7 \%$ and $7.1 \%$ respectively [20].

In this study it was found that females were more affected than males. The relationship between domestic sheep, dogs and humans is very close in the region, and women that have agricultural occupations and work as traditional livestock farmers are more directly exposed to these animals. On the other hand, women who are housekeepers in urban areas are mostly exposed to raw vegetables for daily diet consumption and may consume $E$. granulosus eggs. Studies elsewhere in the country found that the rate of infection in urban areas was greater than rural areas [21], but our findings contradicted
Table 1 Demographic and clinical characteristics of 291 cases of human hydatidosis in hospitals of Kermanshah, Islamic Republic of Iran from 2004-2009 Variable No. of cases $\%$ Total 291 100.0

Sex

Male 141 48.5

Female

150

51.5

Age (years)

1-10

7

11-20

21-30

13

31-40

18

41-50

14

51-60

16

61-70

71-80

8

$80+$

16

Residence

Urban 168

57.7

Rural

42.3

Site

Liver $^{\mathrm{a}}$

64.9

Lung $^{\mathrm{a}}$

26.8

Pelvic area

1.7

Kidney

0.7

Omentum

0.7

Spleen

0.7

Pancreas

0.7

Adrenal gland

0.7

Gallbladder

0.7

Prostate

0.7

Bladder

0.7

Uterus

0.3

Mesentery

Vertebrate

Type

Primary hydatid cyst 273

93.8

Secondary hydatid cyst

6.2

\section{Treatment}

Albendazole

79.4

No albendazole

20.6

${ }^{a}$ Both liver and lung: 3 cases (1.0\%).

that. Other studies also showed that patients with hydatid cyst disease were mostly females [16,17,22-25].

In our study, the youngest age of patients with hydatid cyst disease was between 1-10 (6.9\%) years of age and the
2 oldest cases were over 80 years of age (2.1\%), but the highest rate of hydatid cyst was between 31-40 years of age (17.5\%). A study in Iraq found that the mean age of patients with hydatidosis was 31 years of age [26]. Other studies 
observed the highest number of infected cases in north-west Islamic Republic of Iran were in the age group 20-40 years [1], and in the northern region of the country in the ages $21-30$ years [23]. The highest rate of hydatidosis cases throughout the country were between ages 20-29 years.

Most hydatid cyst organ operations are done on the liver and the rate of liver operations is higher than any other organs [23]. Our study recognized the rate of organ operations on pelvic area, kidney omentum, spleen, pancreas, adrenal glands, gallbladder, uterus, mesenteric area, prostate and bladder were lower than the lung and liver. Recent surgeries reported a rare case of perianal hydatid cyst in Kermanshah province from a rural area [27]. Other investigations identified an infrequent hydatid cyst in the thyroid [28]. Generally, hydatid cysts can be found in the liver and the lungs of infected adults; however, the lungs were more affected than the liver in paediatric groups [29]. Our study showed that only $1.0 \%$ of cases had simultaneously infection of the lungs and liver. Nevertheless, other studies showed that the rate of simultaneous liver and lung cysts to be as high as $26 \%$ [30] and $12.1 \%$ [16].

In this study, most patients had primary hydatid cyst (93.8\%), whereas $6.2 \%$ with hydatid cyst recurrence were referred to as having secondary hydatid cyst. Another study reported recurrences in only $2 \%$ of cases [31]. Some studies indicated the recurrence rate to be variable and commonly ranged from $1.5 \%-2.5 \%$ [32]. In addition, a study in 2010 observed the recurrence of hydatid disease to be $8 \%$ during a median follow-up period of 33 months. Other studies indicated a reported incidence between $1.1 \%-25 \%$, which may be caused by spilling of the cyst's contents during a previous operation [4]. In Iraq, in which $14.5 \%$ of patients had cystic lesions in the liver or other abdominal organs, no recurrences of hydatidosis were observed, except in 1 patient who was referred to a surgery department as a case of pleural effusion drainage despite albendazole therapy [26]. In contrast, some countries reported no recurrences among 65 patients who had undergone surgical hydatid cyst removal in the liver [22]. Other research groups suggested chemotherapy was needed for recurrence of the disease [33]. Some studies reported secondary ovarian hydatid cyst after a 15-year hepatic involvement and recurrence after 30 months [34]. One case study reported a 34-year-old woman who had a 4-time resection of a hydatid cyst from her abdomen. She later developed respiratory symptoms and more than 800 secondary cysts were removed [35].

In our research, laparotomy removal of hydatid cyst, aspiration, reaspiration of fluid cyst with scolicidal agents, skin resection surgery and pre- and postoperative use of albendazole therapy from 12 weeks to 6 months had been prescribed; $20.6 \%$ of patients did not take albendazole therapy after surgical removal of hydatid cysts. Other studies recommended that preoperative treatment with albendazole is effective in reducing the rate of recurrence [12]. Other surgeons recommended albendazole for 321 -day courses with 10day rest periods between courses and only 1 recurrence was reported from month 1-72 [26]. Some suggested that the frozen-seal technique is safe and effective for the surgical treatment of hydatid disease in non-endemic areas and results showed the recurrence rates and mortality rates were lower [4]. In our study, surgical methods and the use of chemotherapeutic agents such as albendazole were employed, even though the secondary or recurrence rates were higher than in other studies (6.2\%). However, prior to the operation in some cases, albendazole was administered and continued for 6 months after surgery. A review article suggested that albendazole use postoperatively may be necessary, especially for bone treatment for a period of 2 years with praziquantel. This regimen can be employed for multiple recurrences [36]. Other researchers suggest that especially in cases of recurrent intra-abdominal extra-hepatic hydatid cyst without concomitant hepatic cyst(s) presence, treatment with albendazole may lead to disappearance of the recurrent cyst and therefore should constitute a first-line therapeutic option prior to any planned reoperation [37].

In the present study, female housekeepers in urban and suburban areas, aged between 30-50 years old, with liver and lung involvement were the groups most commonly infected with epidemiological hydatid cyst in Kermanshah province. The recurrence rate of secondary primary cyst in all patients was $6.2 \%$. As these results suggest, Kermanshah province should be considered as an endemic region in the medical geography zone. Regions near western Islamic Republic of Iran, including neighbouring countries, should be considered as endemic regions for hydatid cyst disease. Better efforts at prevention of hydatid cyst disease are needed in the area including reducing the secondary rate of hydatid cyst.

Competing interests: None declared.

\section{References}

1. Dadkhah MA, Yeganehzad M, Nadery B. Survey on Hydatid cyst infestation in Sarab city (Northwest of Iran) using epidemiological and seroepidemiological criteria. Journal of Animal and Veterinary Advances, 2011, 10:2099-2111.
2. Thompson RCA, Lymbery AJ. Echinococcus. Biology and strain variation. International Journal for Parasitology, 1990, 20:457-470.

3. Torgerson PR, Craig P. Updated global burden of cystic and alveolar echinococcosis. In: Report of the WHO Informal Work- 
ing Group on cystic and alveolar echinococcosis surveillance, prevention and control, with the participation of the Food and Agriculture Organization of the United Nations and the World Organisation for Animal Health, 22-23 June 2011. Geneva, World Health Organization, 2011.

4. Stood JHMB et al. More than 25 years of surgical treatment of hydatid cysts in a nonendemic area using the "frozen seal" method. World Journal of Surgery, 2010, 34:106-113.

5. Hazrati Tappe KH, Mousavi SJ, Barazesh A. Prevalence and fertility of Hydatid cyst in slaughtered livestock of Uremia city, Northwest Iran. Journal of Parasitology and Vector Biology, 2011, 3:29-32.

6. Youssefi MRM et al. Determination of hydatid cyst fluid and protoscolex peptids protective effect in mice. Middle-East Journal of Scientific Research., 2010, 6:667-671.

7. Shahnazi $\mathrm{M}$ et al. Molecular characterization of human and animal Echinococcus granulosus isolates in Isfahan, Iran. Acta Tropica, 2011, 117:47-50.

8. Mamishi S, Sagheb S, Pourakhabari B. Hydatid disease in Iranian children. Journal of Microbiology, Immunology, and Infection, 2007, 40:428-431.

9. khlaghi L, Massoud J, Housaini A. Observation on hydatid cyst infection in Kordestan province (west of Iran) using epidemiological and seroepidemiological criteria. Iranian Journal of Public Health, 2005, 34:73-75.

10. Pezeshki A et al. Analysis of hydatid cyst surgeries in Tehran Milad Hospital, Iran, during 2001-2004. Pakistan Journal of Medical Sciences, 2007, 23:138-140.

11. Mirshemirani AR, Razavi S, Sadeghian S. Surgical treatment of pulmonary hydatid cyst in 72 children. Tanaffos, 2009, 8:56-61.

12. Ghafouri A, Nasiri S. Isolated primary hydatid disease of omentum, report of a case and review of the literature. Iranian Journal of Medical Sciences, 2010, 35:259-261.

13. Hamzavi $Y$, Vejdani $M$, Nazari $N$. The trend of hydatidosis in Kermanshah province, western Iran (1986-2008). Iranian Journal of Parasitology, 2011, 6:33-40.

14. Eftekhar M, Athari A. Five year survey of human hydatidosis in Iran. In: National Congress of Hydatid Cyst, 9-11 April 2007. Yasuj, Islamic Republic of Iran, Yasuj University of Medical Sciences, 2007.

15. Yousefi H. Situation of hydatid cyst infection during last two decades (1985-2005) in Iran (review of articles). Journal of Shahrekord University of Medical Sciences, 2008, 10:78-88.

16. Nourjah $\mathrm{N}$ et al. Study of 4850 operated hydatidosis cases in Iran, Southeast Asian Journal of Tropical Medicine and Public Health, 2004, 35(1):218-222.

17. Brunetti E, Cunha BA. Echinococcosis hydatid cyst. Medscape reference [online] (http://emedicine.medscape.com/ article/216432-overview, accessed 9 May 2013).

18. Ozyurtkan MO, Balci AE. Surgical treatment of intrathoracic hydatid disease: a 5-year experience in an endemic region. Surgery Today, 2010, 40:31-37.

19. Ould Ahmed Salem CB et al. Epidemiological studies on Echinococcosis and characterization of human and livestock hydatid cyst in Mauritania. Iranian Journal of Parasitology, 2011, 6:49-57.

20. Dalimi A et al. Echinococcosis/hydatidosis in western Iran. Veterinary Parasitology, 2002, 105:161-171.

21. Heidari $Z$ et al. Seroepidemiological study of human hydatidosis in Meshkinshar district, Ardabil province, Iran. Iranian Journal of Parasitology, 2011, 6:19-25.

22. Mousavi SR, Khoshnevis J, Kharazm P. Surgical treatment of hydatid cyst of the liver: drainage versus omentoplasty. Annals of Hepatology, 2005, 4:272-274.

23. Esfandiari B et al . Evaluation of hydatid cyst surgeries in Northern Iran Mazandaran province during 2001-2007. Journal of Animal and Veterinary Advances, 2010, 9(7):1128-1130.

24. Kebede N, Mitiku A, Tilahun G. Retrospective survey of human hydatidosis in Bahir Dar, north-western Ethiopia. Eastern Mediterranean Health Journal, 2010, 16:937-941.

25. Mirzanejad-AsI H et al. Seroepidemiology and sonographical survey of Hydatid disease in Moghan plain of Iran. Research Journal of Medical Sciences, 2010, 4:75-80.

26. Yousif Al-amran FG. Surgical experience of 825 patients with thoracic hydatidosis in Iraq. Indian Journal of Thoracic Cardiovascular Surgery, 2008, 24:124-128.

27. Soleimani H, Seifi M, Shemshadi M. Aprimary Hydatid cyst infestation as perianal abscess:Acase repot. Journal of Isfahan Medical School, 2011, 29:491-494.

28. Hajinasrollah E, Motevali S, Sharifian HA. Hydatid cyst of thyroid: a case report. Iranian Journal of Clinical Infectious Diseases. 2007, 2:155-157.

29. Yadollahi M, Farahmand M. Echinococcosis: an occupational disease. International Journal of Occupational and Environmental Medicine, 2010, 1(2):88-91.

30. Mamishi S, Sagheb S, Pourakbari B. Hydatid disease in Iranian children. Journal of Microbiology, Immunology, and Infection, 2007, 40:428-431.

31. Mirshemirani A et al. Liver hydatid cyst in children (a 14-year review). Iranian Journal of Pediatrics, 2011, 21:385-389.

32. Fatimi $\mathrm{SH}$ et al. Hydatid cyst disease of the thorax. Reviews in Infection, 2010, 1(1):42-48.

33. Atmatzidis KS, Pavlidis TE, Papaziogas BT. Recurrence and long term outcome after open cystectomy with omentoplasty for hepatic disease in an endemic area. Acta Chirurgica Belgica, 2005, 105:198-202.

34. Khosravi Maharriooei $M$ et al. Hydatid cyst of ovary: a case report. Iranian Journal of Medical Sciences, 2009, 34:76-79.

35. Khowaja AA et al. Extrapleural hydatid disease of chest: a case of recurrence hydatid disease. Journal of the Pakistan Medical Association, 2008, 58:569-571.

36. Emami MJ et al. Primary hydatid disease of the ilium: a case report. Iranian Red Crescent Med Journal, 2010, 12:190-194.

37. Michail OP et al. Disappearance of recurrent intra-abdominal extra hepatic hydatid cyst following oral albendazole administration. West Indian Medical Journal, 2007, 56:372-375. 